\title{
Fine structural appearances of glomerular capillaries in a case of malignant hypertension
}

\author{
R. F. MACADAM
}

From the University Department of Pathology, Western Infirmary, Glasgow

SYNOPSIS The fine structural features of the glomerular capillary wall in a human case of malignant hypertension are described. The capillaries in glomeruli unaffected by ischaemic necrosis show a constant abnormality consisting of an accumulation of heterogeneous material between the endothelium and basement membrane. This produces very considerable narrowing of the capillary lumen, an appearance which has been described only once before (Robson, Martin, Ruckley, and MacDonald, 1968 ) in four cases of postpartum renal failure.

\section{MATERIALS AND METHODS}

An open renal biopsy was carried out on a 55-year-old man in the accelerated (malignant) phase of a hyperReceived for publication 16 January 1969.

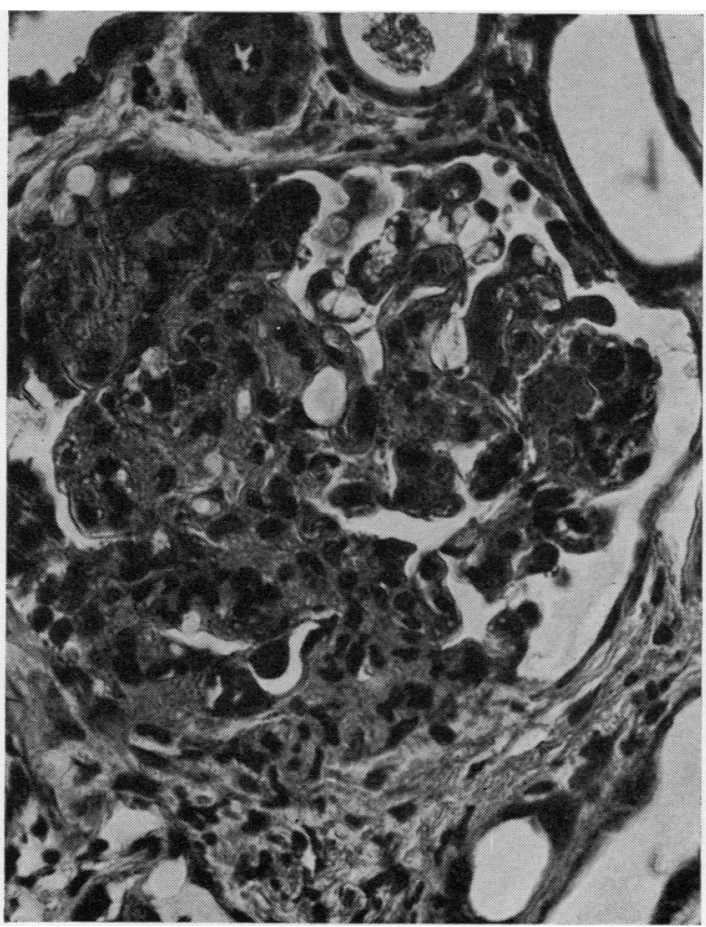

FIG. 1. Glomerulus with partial necrosis. $\times 212$. tensive state which did not respond to any form of therapy. The bulk of the tissue was fixed sequentially in $10 \%$ formol saline and corrosive formalin and embedded in paraffin wax. The tissue for electron microscopy was fixed in $2 \%$ phosphate-buffered glutaraldehyde, post-

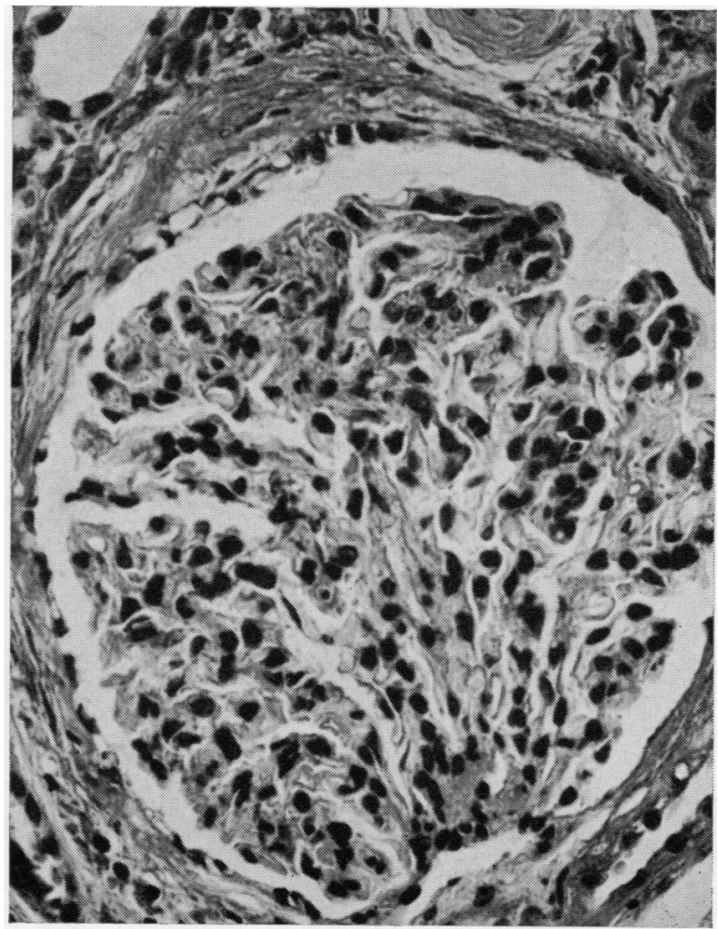

FIG. 2. Non-necrotic glomerulus appearing solid. $\times 212$. 


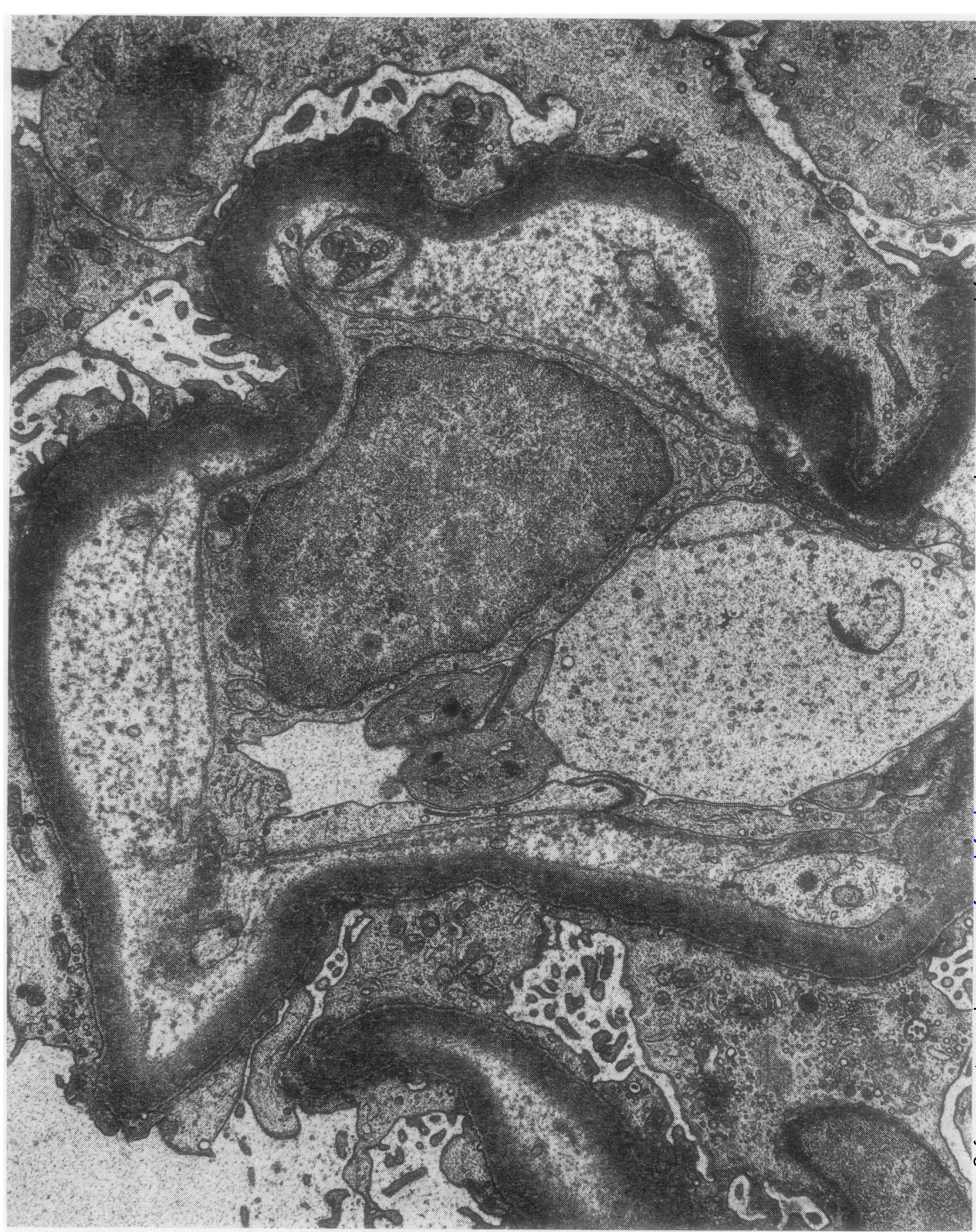




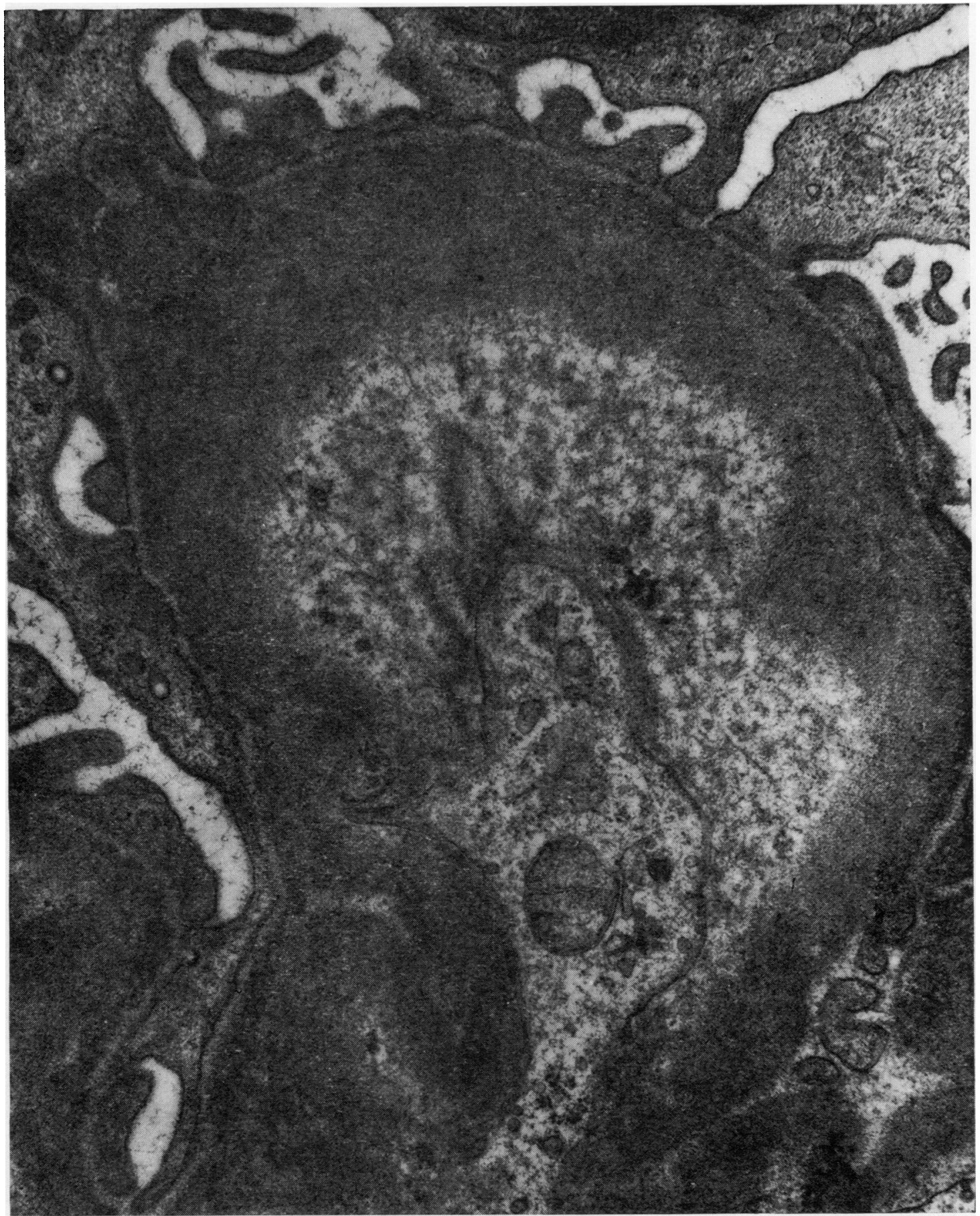

FIG. 4. A higher magnification of the electron micrograph of Fig. 3 showing the microgranular and microfibrillar constituents of the subendothelial material. $\times 41,000$. 




FIG. 5. Interstitial capillary showing no abnormality. $\times 24,500$. 
osmicated and embedded in Araldite. Ultrathin sections were doubly stained with uranyl acetate and lead citrate.

\section{RESULTS}

Light microscopy confirmed the renal histopathological picture of the malignant accelerated phase of a hypertensive state. A partly necrotic glomerulus is seen in Figure 1. The majority of the glomeruli were not necrotic but showed a rather solid tuft architecture with few patent capillary lumina (Fig. 2). Three glomeruli, unaffected by ischaemic necrosis, were selected for and examined by electron microscopy. All capillaries in the three nephrons exhibited the changes illustrated in Figures 3 and 4. The visceral epithelial cells showed extensive focal fusion of foot processes. The basement membrane was of normal thickness and density. The endothelial cells were bulkier than normal. The core of lining endothelial cells was everywhere separated from the basement membrane by a very substantial heterogeneous layer, which was partly microgranular, partly microfibrillar, and partly amorphous. The collar of material in capillary transverse sections had a width of up to $1 \cdot 4 \mu$. The capillary lumen was very considerably reduced by this subendothelial material. The isolated core of endothelial cells appeared to be limited by a very delicate basement membrane. The relationship of endothelium to basement membrane in interstitial renal capillaries was normal (Fig. 5).

\section{DISCUSSION}

The fine structural appearances of glomerular capillaries in this case of malignant hypertension correspond very closely to those reported by Robson et al (1968). In their four cases and in the presently reported one, severe intrarenal arterial and arteriolar narrowing was present. It may be that a subnecrotic degree of ischaemia of the glomerular capillaries is the major factor in the production of this peculiar subendothelial entity. The solid appearance of the non-necrotic glomeruli is probably the light microscopic reflexion of the subendothelial collar of material. Artefactual production of this feature after fixation has not been reported and autolytic changes in glomeruli (Cook, Osvaldo, Jackson, and Latta, 1965) do not mimic this picture. Whatever the precipitating factor, the resultant subendothelial lesion, by substantially reducing the capillary lumen, must exaggerate the state of poor intrarenal blood circulation already produced by the arterial and arteriolar states.

I wish to thank Dr A. Linton for permission to use the biopsy material in this case.

\section{REFERENCES}

Cook, M. L., Osvaldo, L., Jackson, D. J. and Latta, H. (1965). Lab. Invest., 14, 623.

Robson, J. S., Martin, A. M., Ruckley, V. A. and MacDonald, M. K. (1968). Quart. J. Med., 37, 423. 